\section{Revista Facultad 2020 de Ciencias Económicas Vol. 28(2)}

julio-diciembre 2020
- ISSN: 0121-6805 - ISSN-e: 1909-7719

\title{
Estructura del presupuesto de los gobiernos locales y calidad de vida en ciudades chilenas*
}

\author{
Felipe Hernán Torres-Guzmánª - César Antonio Salazar-Espinoza ${ }^{b}$
}

\begin{abstract}
Resumen: Los gobiernos locales gobiernan con el propósito de ofrecer una mejor calidad de vida, de modo que es relevante la focalización del gasto y su capacidad de generar ingresos. Esta investigación utiliza datos de un panel de 93 ciudades chilenas para las cuales se mide la calidad de vida urbana en el periodo 2012-2016, a fin de evaluar los efectos que tiene la estructura del presupuesto sobre la calidad de vida urbana. Para esto se utiliza un modelo probit ordenado con efectos aleatorios. Los resultados muestran un efecto positivo del gasto municipal, ingresos permanentes e inversión en el ranquin de ciudades con diferencias entre las dimensiones del indicador.
\end{abstract}

Palabras clave: calidad de vida urbana; gasto municipal; gobiernos locales

JEL: H720, I310, C25

Fecha de recepción: 1/04/2020 Fecha de aprobación: 29/06/2020

Disponible en línea: 22/12/2020

Cómo citar: Torres-Guzmán, F. H. y Salazar-Espinoza, C. A. (2020). Estructura del presupuesto de los gobiernos locales y calidad de vida en ciudades chilenas. Revista Facultad de Ciencias Económicas, 28(2). https://doi.org/10.18359/rfce.4701

* Artículo derivado del Centro de Estudios Ñuble, un centro de investigación enfocado en explorar problemáticas locales que se vinculan con el territorio en los ámbitos de la economía, la participación ciudadana, el medio ambiente, el género y el desarrollo rural.

a Magíster en Gestión de Empresas, Ingeniero Civil. Universidad del Bío-Bío, Chillan, Chile. Correo electrónico: fhtorres@ubiobio.cl

b Ph. D. en Economía, Magíster en Economía, Ingeniero Comercial. Departamento de Gestión Empresarial y Centro de Estudios Ñuble, Universidad del Bío-Bío y Centro Nenre-EfD, Chillan, Chile. Correo electrónico: csalazar@ubiobio.cl ORCID: http://orcid.org/0000-0002-0199-7688 


\section{Budget Structure of Local Governments and Quality of Life in Chilean Cities}

Abstract: Local governments intend to offer a better quality of life; so, their targeting of spending and ability to generate income are relevant. This research uses data from a panel of 93 Chilean cities evaluated for the effects of budget structure on the quality of urban life between 2012-2016. For this, an ordered probit model with random effects is used. The results show a positive impact of municipal spending, permanent income, and investment on the studied cities with differences among the indicator's dimensions.

Keywords: quality of urban life; municipal spending; local governments

\section{Estrutura orçamentária dos governos locais e qualidade de vida em cidades chilenas}

Resumo: Os governos locais governam com o objetivo de oferecer uma melhor qualidade de vida, portanto é relevante o foco da despesa e sua capacidade de gerar ingressos. Esta pesquisa utiliza dados de um painel de 93 cidades chilenas para as quais a qualidade de vida urbana é medida no período de 2012-2016, a fim de avaliar os efeitos que a estrutura orçamentária tem sobre a qualidade de vida urbana. Para isso, é utilizado um modelo probit ordenado com efeitos aleatórios. Os resultados mostram um efeito positivo da despesa municipal, ingressos permanentes e investimento no ranking de cidades com diferenças entre as dimensões do indicador.

Palavras-chave: qualidade de vida urbana; despesa municipal; governos locais 


\section{Introducción}

El desarrollo local urbano se define como el proceso que propende a lograr una mejor calidad de vida al propiciar mayor bienestar económico, social, cultural, político, científico, tecnológico y ambiental para la población que reside en un determinado territorio (Bonet, Zapata y Rueda, 2012). Las dificultades de accesibilidad, el deterioro del medio construido, la dificultad de las relaciones sociales, la pobreza, la inseguridad social y la saturación de los servicios son algunos de los problemas que caracterizan hoy a los contextos urbanos y que influyen en la calidad de vida de sus habitantes. Chile se encuentra en un nivel de desarrollo en el que las expectativas de su población han aumentado, de modo que demanda objetivos relacionados no solo con la superación de las condiciones mínimas de habitabilidad, sino, más bien, con aspectos de mayor complejidad, tales como la creación de un ambiente atractivo para los negocios, mejor infraestructura que facilite la movilidad y la demanda de espacios con menos contaminación ambiental, entre otros (Orellana, 2011). Lo anterior plantea nuevos desafíos en la medición de la calidad de vida actual de las ciudades.

El objetivo principal de los gobiernos locales o las municipalidades es crear las condiciones que permitan satisfacer las necesidades de sus habitantes y asegurar así el bienestar económico, social y cultural de cada comuna (Fuentes, Allard y Orellana, 2007). Este propósito se logra mediante la implementación de proyectos de inversión y políticas públicas con un sentido de priorización. Asimismo, el seguimiento y la evaluación de los resultados de alguna estrategia o política, en relación con su capacidad de generar bienestar, debe, en algún momento, medirse en términos de indicadores de calidad de vida de los territorios. De esta manera, el estudio de los indicadores de impacto de las políticas emerge como una herramienta de control para asegurar la eficacia y la eficiencia en la toma de decisiones, así como para el diseño de mejores políticas locales (Lambiri, Biagi y Royuela, 2007).

En razón a lo anterior, surge la necesidad de explorar la existencia de patrones que vinculen la gestión municipal, en términos de estrategias de uso y priorización de recursos, con indicadores que den cuenta de cambios en las condiciones de vida de los habitantes. Gyourko y Tracy (1991) plantean que los gobiernos locales pueden incidir sobre la calidad de vida urbana local por medio de un buen uso de sus herramientas fiscales. Pacheco, Sánchez y Villena (2013) encuentran que los municipios en Chile que destinan una mayor parte de sus recursos a inversión son más eficientes en la provisión de bienes públicos locales tales como educación, salud, recolección de basura y mantenimiento de áreas verdes, entre otros, variables que se vinculan estrechamente a la mirada integral del concepto de calidad de vida urbana.

El objetivo de este trabajo es evaluar la relación entre la estructura de gastos, ingresos e inversión municipal y el nivel de calidad de vida urbana. La hipótesis de este estudio es que municipalidades con una estructura de su presupuesto con una mayor importancia de la inversión e ingresos generados de manera autónoma presentan un nivel de calidad de vida urbana más alta.

Para esto se estima un modelo probit ordenado para datos de panel con efectos aleatorios utilizando datos de medición de calidad de vida urbana $\left(\mathrm{ICVU}^{1}\right)$ para un conjunto de comunas de Chile en el periodo 2012-2016. A fin de caracterizar la estructura de ingresos y gastos municipales se utiliza información del Sistema Nacional de Información Municipal $\left(\operatorname{Sinim}^{2}\right)$.

El resto de este artículo se organiza como sigue. La segunda sección describe la estructura de gastos, ingresos e inversión de los gobiernos locales. La tercera discute el concepto de calidad de vida

1 ICvu es el Índice de Calidad de Vida Urbana construido por el Instituto de Estudios Urbanos de la Pontificia Universidad Católica de Chile, y apoyado por la Cámara Chilena de la Construcción (сCHC).

2 El Sinim es una plataforma de gestión que recopila y pone a disposición de la ciudadanía un conjunto de variables y datos estadísticos municipales asociados a diversas áreas de la gestión local. El sistema se alimenta también con la información proporcionada por otros organismos del Estado. 
urbana, mientras que la cuarta revisa la literatura relevante. La quinta sección presenta los datos, la sexta explica el modelo empírico y la séptima discute los resultados. Finalmente, la octava concluye.

\section{Estructura de financiamiento de los gobiernos locales}

De acuerdo con la Ley N. 18.695 , una municipalidad se define como la unidad encargada de la administración local de cada comuna. La gestión de este territorio es responsabilidad del alcalde (máxima autoridad) y de un Concejo Municipal como órgano resolutivo, nominativo y fiscalizador de la autoridad, los cuales se eligen para un periodo de cuatro años.

El marco legal chileno define a los municipios en Chile como "corporaciones autónomas de derecho público, con personalidad jurídica y patrimonio propio, cuyo objetivo es satisfacer las necesidades de la comuna y asegurar la participación de sus habitantes en el progreso económico, social y cultural". Las responsabilidades de las municipalidades se enmarcan dentro de la gestión de los espacios públicos, la infraestructura comunal, la movilización vehicular, los servicios de limpieza y la gestión de residuos, así como de la regulación del área urbana. De esta manera, las municipalidades tienen el rol de gobernar, ejercer autoridad y promover iniciativas dentro de cada comuna que puedan beneficiar y cumplir las demandas de sus habitantes (Fuentes et al., 2007).

Los ingresos con los que cuentan las municipalidades se categorizan en función del origen de su financiamiento, dado que provienen, básicamente, de dos fuentes: ingresos propios permanentes (IPP) y Fondo Común Municipal (FCM). Otros ingresos comprenden las transferencias corrientes y de capital. Los ingresos propios permanentes (IPP) son aquellos ingresos que es capaz de generar la comuna a partir de su gestión municipal, es decir, es un indicador que mide la capacidad de autofinanciamiento del municipio. Los ingresos que se generan de manera autónoma no presentan mayores restricciones en cuanto a su inversión y, por tanto, pueden utilizarlos libremente los municipios. Los ingresos propios permanentes provienen, principalmente, desde recaudación de patentes municipales, derecho de aseo, concesiones o rentas a la propiedad municipal, y una parte del ingreso proveniente del impuesto territorial y de los permisos de circulación, entre otros de menos importancia. Las fuentes de ingreso propias más importantes son: a) el impuesto territorial a los bienes raíces agrícolas y no agrícolas cuya operación e implementación se encuentra normado por la Ley N. ${ }^{\circ} 17.235^{3}$; las patentes comerciales ${ }^{4}$, cuya recaudación está a cargo de cada municipalidad ${ }^{5}$; y los permisos de circulación, los cuales, del total recaudado, el 37,5\% es de beneficio directo municipal, mientras que el 64,5\% complementa el FCM.

El FCM es un fondo de recursos que se crea a fin de estar en capacidad de redistribuir los ingresos desde comunas de altos ingresos a comunas más pobres, con el objeto de que estas puedan cumplir con sus funciones y operar de manera adecuada. El mecanismo de distribución de estos recursos está normado por la ley de rentas municipales, la cual considera un $25 \%$ para todas las comunas, un $10 \%$ que está en función del nivel de pobreza de la comuna relativa al país, un $30 \%$ de predios exentos del impuesto territorial de cada comuna relativa al país y, finalmente, un $35 \%$ de los ingresos propios permanentes (Pacheco et al., 2013).

Finalmente, los recursos municipales también provienen desde transferencias recibidas desde el resto del sector público, principalmente, desde fondos provenientes del gobierno central, los cuales son restringidos para financiar programas sectoriales y

3 En el caso de las cuatro comunas más grandes (Santiago, Providencia, Las Condes y Vitacura) los porcentajes son del $35 \%$ y el $65 \%$, respectivamente.

4 Del monto recaudado por patentes comerciales, solo cuatro municipalidades deben donar una parte al FCM: la municipalidad de Santiago aportando un 55 \%, y las municipalidades de Las Condes, Providencia y Vitacura un 65 \%.

5 De este ingreso, un $40 \%$ es otorgado al municipio para ser utilizado descentralizadamente, mientras que el $60 \%$ restante se destina al Fondo Común Municipal (FCM). 
políticas públicas. Estos proyectos son diversos y se enmarcan en las áreas de educación pública, salud primaria, vivienda, protección social, seguridad, urbanismo y otros proyectos de inversión financiados por el Fondo Nacional de Desarrollo Regional (FNDR) (Henríquez et al., 2011).

Una clasificación alternativa de los gastos municipales considera las siguientes categorías: gastos en personal, bienes y servicios de consumo, prestaciones de seguridad social, transferencias corrientes, íntegros al fisco, adquisiciones de activos no financieros y financieros, iniciativas de inversión, préstamos, transferencias de capital, servicios de deuda y saldo final de caja. Asimismo, los gastos del presupuesto comunal, en lo que respecta a la formulación, ejecución e información, se pueden desagregar por áreas de gestión tales como gestión interna, servicios a la comunidad, actividades municipales, programas sociales, programas recreacionales y programas culturales.

Finalmente, el gasto de inversión comunal se encuentra en función de la capacidad de gestión de cada municipalidad para financiar proyectos de interés de cada territorio. Los recursos que se asignan a estos proyectos de inversión provienen tanto desde financiamiento propio como desde fondos externos, entre los cuales se encuentran los fondos regionales, o los que provienen de otros organismos del Gobierno nacional. Los proyectos financian gastos e inversión en sectores tales como educación, salud, saneamiento, vialidad, electrificación, áreas verdes y equipamiento urbano.

\section{Calidad de vida urbana}

La demanda creciente de la ciudadanía y las competencias que tienen hoy los centros urbanos por atraer inversiones y recursos humanos calificados, implica elevar los niveles de calidad de vida, de modo que es esta unas de las principales preocupaciones en el diseño de estrategias de desarrollo local, regional y nacional en los países. En este contexto, a nivel de las ciudades, uno de los desafíos más importantes que emergen se relaciona con la formulación e implementación de indicadores que den cuenta de avances y logros dentro de un sistema de seguimiento y evaluación que entregue información relevante y actualizada sobre los impactos de las políticas públicas (Leva, 2005).

La calidad de vida urbana se percibe como un medio para medir y evaluar el bienestar, la satisfacción o la felicidad de las personas de un determinado territorio (Fadda et al., 2002, p. 3). La calidad de vida urbana se materializa en un conjunto de indicadores, los cuales no solo consideran una dimensión objetiva, sino también una subjetiva asociada a la percepción y las características del sujeto en relación con su estilo y sus niveles de vida. Así, la mayoría de los autores conciben la calidad de vida como una construcción compleja y multidimensional sobre la que pueden desarrollarse algunas formas de medida objetivas a través de una serie de indicadores, en los que tiene un importante peso específico la vivencia que el sujeto pueda tener de sí mismo (Precedo et al., 2012). Consecuentemente, el concepto de calidad de vida urbano no se limita al nivel de vida personal, sino que integra todos los elementos (objetivos y subjetivos) de las condiciones en que viven las personas de una comunidad urbana, tanto de sus necesidades como de sus percepciones, expectativas y satisfactores.

Así, por ejemplo, Lambiri et al. (2007) proponen una clasificación general y una agrupación de indicadores de calidad de vida urbana en función de, al menos, seis categorías: medio ambiente natural (clima, estado de medioambiente natural, etc.); entorno construido (tipo y nivel de construcciones); entorno sociopolítico (vida comunitaria, participación política, etc.); entorno económico local (ingreso local, desempleo, etc.); entorno de cultura y ocio (museos, restaurantes); entorno políticas públicas (seguridad, salud, educación y provisión, etc.).

Existe un número de estudios desarrollados por organizaciones nacionales e internacionales que publican clasificaciones de ciudades basadas en indicadores ponderados de calidad de vida urbana. Uno de los primeros ejemplos de ranquin de ciudades fue el Placed Rated Almanac ${ }^{6}$, de 1981, el cual se diseñó para clasificar las ciudades de Estados Unidos. Otro ejemplo es el European Cities Monitor Report, el cual elabora un ranquin de las principales ciudades de Europa de acuerdo con su

6 The Places Rated Almanac aún se publica. 
atractivo para hacer negocios, su disponibilidad y el costo de la mano de obra, del transporte y las telecomunicaciones (Lambiri et al., 2007). En Italia, el periódico Il Sole 24 Ore publica anualmente "The Dossier Sull'Italia: Qualita Vita", con un ranquin de 103 provincias italianas, basado en un grupo de indicadores dentro de seis dimensiones: estándar de vida, empleo y negocios, servicios, crimen, población y ocio. Finalmente, en España, el Anuario Social de España incluye un ranquin de provincias y ciudades en ocho dimensiones: características de población, distribución territorial de población, demografía, migración, alojamiento, empleo, niños y tercera edad.

\section{Revisión de la literatura}

Las primeras aproximaciones orientadas a medir diferencias en calidad de vida de las ciudades se basaron en el método de los precios hedónicos, el cual se basa en la valoración de los atributos de las localidades. Debido a la inexistencia de valores efectivos para estos atributos, esta metodología propone la utilización de precios de mercado de la vivienda y los salarios a fin de realizar aproximaciones al valor de los distintos atributos. De esta manera, los valores implícitos de los atributos locales se pueden calcular y luego usar por separado o dentro de un índice de calidad de vida, para, de esta manera, clasificar las ciudades.

Uno de los primeros autores en aplicar este método para medir la calidad de vida en las ciudades fue Rosen (1979). El autor midió la calidad de vida en algunas ciudades norteamericanas sobre la base de indicadores salariales, calculando la contribución a los salarios de diferentes factores tales como el costo de vida, el capital humano y otros atributos positivos y negativos relevantes, con el objeto de explicar la elección de los trabajadores por una ciudad. Siguiendo a Rosen, muchos autores han aplicado esta metodología, con variaciones en la forma funcional de los modelos e indicadores incluidos en la medición de la calidad de vida (véase, por ejemplo, Blomquist, Berger y Hoehn, 1988; Giannias, 1998; Gyourko y Tracy, 1991; Roback, 1982; Stover y Leven, 1992).
Uno de los primeros estudios que propone una incidencia de las variables fiscales en la calidad de vida en las ciudades fue la investigación desarrollada por Gyourko y Tracy (1991). Los autores exploran el efecto de un conjunto de factores en los diferenciales de compensación en los mercados locales de propiedades y trabajo en las áreas metropolitanas de las ciudades de Estados Unidos. Las estimaciones muestran efectos significativos de variables ambientales tales como precipitación, temperatura y contaminación, así como variables económicas y de provisión de servicios relacionadas con el costo de vida, la educación, la salud y la participación comunitaria. En particular, los autores destacan la contribución positiva del clima fiscal en la calidad de vida urbana, con lo cual muestran que las diferencias en las condiciones fiscales locales generan diferenciales de compensación en los mercados locales de propiedades y trabajo.

El rol de los recursos fiscales también lo destacan Precedo et al. (2012), quienes exploran los niveles de calidad de vida en siete áreas urbanas gallegas en España. Los resultados muestran una relación estadísticamente significativa entre calidad de vida urbana y los niveles de atracción, accesibilidad, desarrollo económico y seguridad ciudadana, destacando también una incidencia positiva del gasto público y la calidad de vida urbana. El autor concluye que las ciudades con mejor calidad de vida son, en particular, aquellas más competitivas desde un punto de vista económico. En relación con aspectos subjetivos relacionados con la calidad de vida, Appleton (2008) explora diferencias en los niveles de satisfacción con la vida en la China urbana. Los resultados muestran que mayores tasas de desempleo inciden de forma negativa en la satisfacción con la vida urbana. En contraste, se encontró que individuos con mayores ingresos, mejor estado de salud y estatus matrimonial tienen niveles de satisfacción con la vida más altos.

\section{Datos}

\section{Indicador de calidad de vida urbana}

Este trabajo utiliza la información del Índice de Calidad de Vida Urbana (ICVU) construido por el Instituto de Estudios Urbanos de la Pontificia 
Universidad Católica de Chile y apoyado por la Cámara Chilena de la Construcción (CCHC). El estudio calcula anualmente, desde el 2012, el ICvU para una muestra de 93 comunas de Chile. Debido a que el índice no se construye con las mismas variables año tras año y las ponderaciones cambian según un panel de expertos, este trabajo utiliza rangos del Índice de Calidad de Vida Urbana en vez del indicador propiamente. Por tanto, se utilizan los datos de los rangos de cinco años hasta el 2016 para cada comuna y sus dimensiones. En particular, se clasifica la comuna en tres rangos de calidad de vida urbana. La definición de cada rango depende del valor promedio de cada índice, de manera que en el caso superior la comuna se encuentra por sobre el promedio del índice, para el rango inferior el índice se encuentra por debajo de la diferencia entre el valor promedio del índice y la desviación estándar, mientras que en el caso promedio el índice se ubica entre ambos rangos. Los datos utilizados de los rangos de calidad de vida urbana por año y ciudades se muestran en la Tabla A1 del Anexo.

Las dimensiones del índice utilizados se detallan a continuación.

- Condición laboral. Considera indicadores que miden el grado de acceso al mercado del trabajo, la generación de ingresos, las oportunidades de capacitaciones, el desarrollo profesional y la protección social de los habitantes de cada comuna.

- Ambiente de negocios. Se refiere a las condiciones económicas que promueven que la ciudad o el territorio presente características favorables para la atracción de inversiones privadas o emprendimientos.

- Condiciones socioculturales. Engloba un conjunto de variables relativas a la participación social, así como el grado de seguridad y las oportunidades en educación que inciden en la formación de capital social.

- Conectividad y movilidad. Comprende indicadores que miden las condiciones de la infraestructura de conectividad, movilidad y seguridad vial de los habitantes de la comuna.

- Salud y medio ambiente. Considera mediciones del estado de la salud de la población en relación con enfermedades que tienen una vinculación más estrecha con problemas ambientales ocasionados por factores de carácter antrópico.

- Vivienda y entorno. Comprende variables que describen aspectos sobre la calidad de la vivienda, el grado de hacinamiento e inversión en los espacios públicos en el entorno de la población comunal.

Para efectos de este trabajo, se explora el Índice General de Calidad de Vida Urbano y las dimensiones que la componen por separado. La información para la construcción de este indicador se obtiene, principalmente, de organismos del Estado, tales como los ministerios de Educación, Salud, el Ministerio de Desarrollo Social, la Subsecretaría del Delito y desde servicios públicos como el Instituto Nacional de Estadísticas (INE), el Servicio de Impuestos Internos (SII) y la Tesorería General de la República.

\section{Indicador de ingresos y gasto municipal}

La estructura de gastos se centra en los gastos municipales totales, el asignado para educación y salud desde los fondos municipales y que pertenece al presupuesto municipal. Mientras que la estructura definida para los ingresos municipales está constituida, principalmente, por los ingresos propios permanentes y los ingresos por permisos de circulación de beneficio municipal. Por su parte, la estructura de inversión está compuesta por la inversión total municipal y la inversión en educación y salud. Todas las variables se extraen del Sinim y están expresadas en millones de pesos per cápita en términos reales.

Finalmente, se incluye un conjunto de variables de control relacionadas con el nivel de profesionalización del personal municipal, metros cuadrados de áreas verdes por habitante, índice de motorización de cada ciudad, el delta temperatura promedio - que es la diferencia entre la máxima y mínima temperatura registrada en grados Celsius - y, finalmente, la variable criminalidad que se construye como las denuncias per cápita para cada ciudad del estudio. Las estadísticas descriptivas de las variables de estructura y gastos municipales, así como las variables de control se muestran en la Tabla 1. 


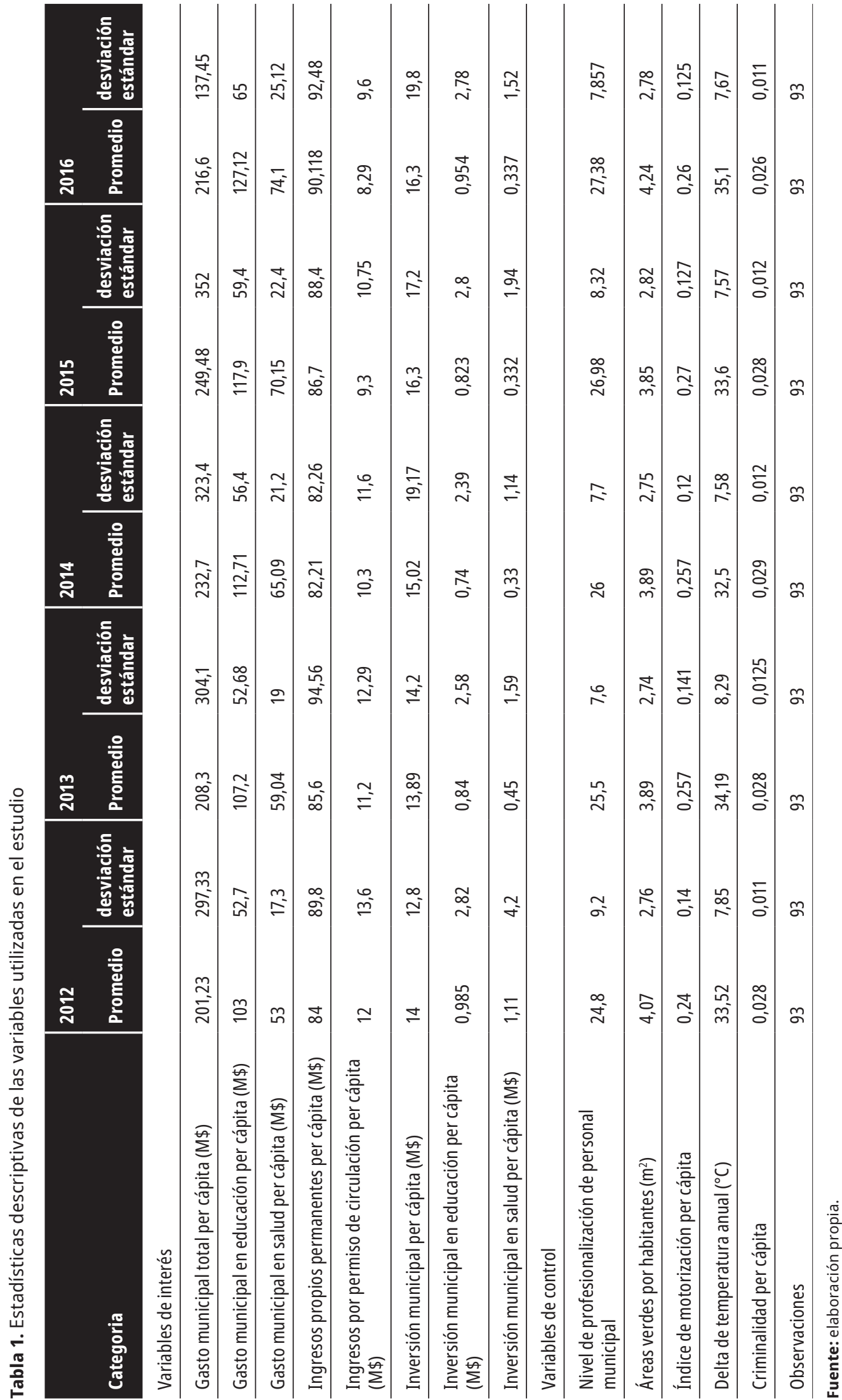


Es posible observar en la Tabla 1 un alza en el promedio del gasto total per cápita en el 2016, mientras que los ingresos propios permanentes muestran un aumento en los dos primeros años de estudio, para luego presentar una baja en el 2014 y un nuevo repunte en el 2016. Se observa también una reducción en los ingresos por permisos de circulación, lo cual se puede deber a que la población de automóviles no va en concordancia con el crecimiento de la población. El comportamiento de la inversión es dispar. Mientras la inversión total municipal per cápita crece levemente y la inversión en salud muestra una tendencia negativa. La inversión en educación muestra solo un alza a partir del 2014. Entre las variables de control, la única que tiene un crecimiento sostenido es el nivel de profesionalización de los municipios. Áreas verdes por metro cuadrado per cápita y criminalidad presentan un comportamiento fluctuante, con un incremento el último año, mientras que las variables delta de temperatura y el índice de motorización no muestran un patrón claro de comportamiento.

\section{Estrategia empírica}

Con la información disponible para cada dimensión del índice, los rangos de calidad de vida urbana se pueden expresar de la siguiente manera:

$L_{i t}=f\left(x_{i t}, d_{i t}\right)$

Donde $L_{i}$ representa tres rangos del Índice de Calidad de Vida Urbana (alta, media o baja) en las diferentes dimensiones $L$ de la que está compuesto el ICvu, $X_{i t}$ representa las variables de control, y $d_{i t}$ representa las variables que explican la estructura de gastos, ingresos e inversión municipal de cada ciudad $i$ en cada año $t$.

Para determinar y cuantificar la asociación entre los rangos y las variables explicativas no es recomendable la utilización de una regresión simple a través del método de mínimos cuadrados ordinarios (MCO), ya que se estaría considerando que las diferencias entre los rangos alto y medio es la misma que entre los rangos medio y bajo, cuando en realidad el valor que representa cada rango simplemente indicaría el orden establecido entre ellos (Greene, 1998). Otra alternativa para modelar los rangos del índice es el modelo probit multinomial que, aunque es aplicable a datos categóricos, no recoge el orden que siguen los rangos de la variable dependiente. Este trabajo propone la estimación de un modelo probit ordenado que, además de tener en cuenta el carácter acotado y discreto de la variable dependiente, considera su ordenación.

Con el fin de estimar econométricamente el modelo se asume el marco conceptual de la variable latente. Bajo este concepto, la definición de la calidad de vida asociada a cada rango y ciudad se asocia con el cálculo de las respectivas probabilidades (Cabrer, Sancho y Serrano, 2001). Para el probit ordenado se asume una función de distribución normal. En el caso en que la variable dependiente pueda tomar más de dos valores, pero a la vez mantener las condiciones de que es una variable discreta, limitada y cuyos valores siguen un orden, es necesario generalizar los modelos de elección binaria para el caso de más rangos. La categoría observada $L_{i t}$ se basa en la variable latente del rango de calidad de vida. Así, las probabilidades asignadas para cada rango se definen en función de umbrales $\gamma$ como sigue:
$L_{i t}=\left\{\begin{array}{cc}1 \mathrm{si} & P_{i} \leq \gamma_{1} \\ 2 \mathrm{si} & \gamma_{1}<P_{i} \leq \gamma_{2} \\ 3 \mathrm{si} & \gamma_{3}<P_{i}\end{array}\right.$ 
En particular, el cálculo de las probabilidades de observar cada uno de los valores $L_{t i}$ viene dada por la siguiente expresión:

$$
\begin{gathered}
\operatorname{Pr}\left(L_{i t}=1 \mid x_{i t}, d_{i t}, \beta_{x}, \beta_{d}, \gamma\right)=F\left[\gamma_{1}-\left(x_{i t} \beta_{x}+d_{i t} \beta_{d}\right)\right] \\
\operatorname{Pr}\left(L_{i t}=2 \mid x_{i t}, d_{i t}, \beta_{x}, \beta_{d}, \gamma\right) \\
=F\left[\gamma_{2}-\left(x_{i t} \beta_{x}+d_{i t} \beta_{d}\right)\right]-F\left[\gamma_{1}-\left(x_{i t} \beta_{x}+d_{i t} \beta_{d}\right)\right] \\
\operatorname{Pr}\left(L_{i t}=3 \mid x_{i t}, d_{i t}, \beta_{x}, \beta_{d}, \gamma\right)=F\left[\gamma_{3}-\left(x_{i t} \beta_{x}+d_{i t} \beta_{d}\right)\right]
\end{gathered}
$$

Donde $F[\cdot]$ es la función de distribución o de densidad acumulada normal. Tanto los valores de los parámetros $\beta$ como los valores de los umbrales se estiman de forma simultánea través del método de máxima verosimilitud. Se asume un comportamiento aleatorio para el componente fijo en la estructura de panel, mediante la estimación de un modelo probit ordenado con efectos aleatorios.

\section{Resultados}

Las estimaciones se muestran en la tablas 2, 3 y 4, las cuales incluyen diferentes especificaciones con variables rezagadas y efectos sobre las distintas dimensiones. Para la interpretación de los coeficientes resultantes de los modelos se debe entender, en primera instancia, que los rangos van de mayor a menor, es decir, estar en el rango 1 sugiere estar en el tercio superior del ranquin de calidad de vida de las ciudades chilenas, lo que implica una posición mejor en relación con estar en el rango 2 $y$, por consiguiente, con encontrarse en el rango 3. Por ende, un signo positivo que acompañe al coeficiente nos dirá que una ciudad cae en el ranquin, lo que se traduce en una disminución de la calidad de vida urbana para la dimensión analizada. En contraste, si se obtiene un signo negativo la variable en

\begin{tabular}{|c|c|c|c|c|c|c|c|c|}
\hline \multirow{2}{*}{ Gasto municipal } & 0,00311 & 0,00312 & $-0,00667^{* *}$ & $-0,00235$ & $-0,00321^{*}$ & 0,00133 & $-0,00273$ & $-0,00674^{* * *}$ \\
\hline & $(0,00286)$ & $(0,00283)$ & $(0,00281)$ & $(0,00266)$ & $(0,00180)$ & $(0,00291)$ & $(0,00292)$ & $(0,00248)$ \\
\hline \multirow{2}{*}{$\begin{array}{l}\text { Gasto municipal } \\
\text { en educación }\end{array}$} & $-0,00817^{* * *}$ & & $3,10 \mathrm{e}-06^{* *}$ & & & & & \\
\hline & $(0,00224)$ & & $(1,46 \mathrm{e}-06)$ & & & & & \\
\hline \multirow{2}{*}{$\begin{array}{l}\text { Gasto municipal } \\
\text { en Salud }\end{array}$} & 0,00878 & & & & $0,0130^{* *}$ & & & \\
\hline & $(0,00876)$ & & & & $(0,00517)$ & & & \\
\hline
\end{tabular}
cuestión aumenta la calidad de vida urbana.

Tabla 2. Modelo probit ordenado con efecto aleatorio datos de panel rezago $t=0$ años

\begin{tabular}{|c|c|c|c|c|c|c|c|c|}
\hline \multirow{2}{*}{$\begin{array}{l}\text { Ingresos propios } \\
\text { permanentes }\end{array}$} & $-0,0113^{* *}$ & $-0,00930$ ** & 0,00261 & $-0,00274$ & $-0,00613^{* *}$ & $-0,00909 * *$ & $-0,00482$ & $-0,00148$ \\
\hline & $(0,00473)$ & $(0,00434)$ & $(0,00283)$ & $(0,00306)$ & $(0,00252)$ & $(0,00418)$ & $(0,00352)$ & $(0,00282)$ \\
\hline \multirow{2}{*}{$\begin{array}{l}\text { Ingreso permiso } \\
\text { circulación }\end{array}$} & $-0,00716$ & & & 0,00224 & & & & \\
\hline & $(0,0117)$ & & & $(0,0106)$ & & & & \\
\hline
\end{tabular}

\begin{tabular}{|l|l|l|l|l|l|l|l|}
\hline Variables & Rango IcvU & $\begin{array}{l}\text { Rango } \\
\text { ICVU }\end{array}$ & $\begin{array}{l}\text { Rango } \\
\text { sociocultural }\end{array}$ & $\begin{array}{l}\text { Rango } \\
\text { conectividad }\end{array}$ & $\begin{array}{l}\text { Rango } \\
\text { salud }\end{array}$ & $\begin{array}{l}\text { Rango } \\
\text { laboral }\end{array}$ & $\begin{array}{l}\text { Rango } \\
\text { negocios }\end{array}$ \\
\hline
\end{tabular}

Estructura de ingresos municipales per cápita 


\section{Estructura de inversión municipal per cápita}

\begin{tabular}{|c|c|c|c|c|c|c|c|c|}
\hline \multirow{2}{*}{$\begin{array}{l}\text { Inversión } \\
\text { municipal }\end{array}$} & 0,00581 & $-0,000235$ & $-0,00855$ & $-0,00186$ & 0,00586 & $-0,00274$ & 0,00497 & 0,00146 \\
\hline & $(0,00643)$ & $(0,00686)$ & $(0,00737)$ & $(0,00934)$ & $(0,00796)$ & $(0,00784)$ & $(0,00984)$ & $(0,00618)$ \\
\hline \multirow{2}{*}{$\begin{array}{l}\text { Inversión en } \\
\text { educación }\end{array}$} & 0,00899 & & 0,0233 & & & & & \\
\hline & $(0,0242)$ & & $(0,0295)$ & & & & & \\
\hline \multirow{2}{*}{ Inversión en salud } & 0,0131 & & & & 0,0104 & & & \\
\hline & $(0,0174)$ & & & & $(0,0304)$ & & & \\
\hline
\end{tabular}

Variables de control

\begin{tabular}{|c|c|c|c|c|c|c|c|c|}
\hline \multirow{2}{*}{$\begin{array}{l}\text { Nivel de } \\
\text { profesionalización }\end{array}$} & $-0,0184$ & $-0,0142$ & $-0,0231^{* *}$ & $-0,00530$ & $-0,00209$ & 0,0101 & 0,00565 & 0,00993 \\
\hline & $(0,0130)$ & $(0,0129)$ & $(0,0115)$ & $(0,00745)$ & $(0,00810)$ & $(0,0151)$ & $(0,0114)$ & $(0,00961)$ \\
\hline \multirow{2}{*}{ Áreas verdes } & $-0,0827^{* *}$ & $-0,102^{* *}$ & $-0,0308$ & $-0,0696$ & $-0,0413$ & 0,0412 & 0,0130 & $-0,106^{* * *}$ \\
\hline & $(0,0372)$ & $(0,0441)$ & $(0,0377)$ & $(0,0459)$ & $(0,0302)$ & $(0,0371)$ & $(0,0442)$ & $(0,0365)$ \\
\hline \multirow{2}{*}{$\begin{array}{l}\text { Índice de } \\
\text { motorización }\end{array}$} & $-0^{* * *}$ & -0 *** & $-0^{* * *}$ & 0 & $-0^{* *}$ & 0 & $0^{* * *}$ & $-0^{* * *}$ \\
\hline & 0 & 0 & 0 & 0 & 0 & 0 & 0 & 0 \\
\hline \multirow{2}{*}{ Temperatura } & 0,00410 & 0,00818 & 0,00621 & $0,0441^{* * *}$ & $-0,00916$ & $-0,00435$ & $-0,0367^{* *}$ & $-0,0175$ \\
\hline & $(0,0139)$ & $(0,0171)$ & $(0,0208)$ & $(0,0141)$ & $(0,00908)$ & $(0,0152)$ & $(0,0144)$ & $(0,0146)$ \\
\hline \multirow{2}{*}{ Criminalidad } & $-16,91$ & $-31,36$ & $-1,829$ & -1667 & $37,28^{* * *}$ & $-18,53^{*}$ & $-69,58^{* * *}$ & 16,49 \\
\hline & $(23,62)$ & $(22,92)$ & $(16,00)$ & $(16,15)$ & $(12,60)$ & $(10,10)$ & $(19,06)$ & $(11,69)$ \\
\hline \multirow[t]{2}{*}{ dummy_12 } & $-0,343$ & $-0,264$ & $-0,354$ & $-0,139$ & 0,191 & 0,152 & $-0,501$ & $-0,511^{* *}$ \\
\hline & $(0,363)$ & $(0,313)$ & $(0,290)$ & $(0,271)$ & $(0,268)$ & $(0,242)$ & $(0,314)$ & $(0,250)$ \\
\hline \multirow[t]{2}{*}{ dummy_13 } & $-0,196$ & $-0,129$ & $-0,529 * * *$ & $-0,140$ & 0,0453 & 0,0203 & $-0,0116$ & $-0,478^{*}$ \\
\hline & $(0,312)$ & $(0,281)$ & $(0,205)$ & $(0,233)$ & $(0,221)$ & $(0,240)$ & $(0,297)$ & $(0,246)$ \\
\hline \multirow[t]{2}{*}{ dummy_14 } & 0,00248 & 0,112 & $-0,175$ & 0,0768 & 0,0678 & 0,0815 & $-0,288$ & $-0,173$ \\
\hline & $(0,277)$ & $(0,261)$ & $(0,216)$ & $(0,193)$ & $(0,221)$ & $(0,226)$ & $(0,277)$ & $(0,201)$ \\
\hline \multirow[t]{2}{*}{ dummy_15 } & $-0,167$ & $-0,0923$ & 0,00596 & 0,0796 & 0,0388 & 0,218 & $-0,0600$ & $-0,434^{* * *}$ \\
\hline & $(0,268)$ & $(0,263)$ & $(0,237)$ & $(0,137)$ & $(0,174)$ & $(0,189)$ & $(0,281)$ & $(0,153)$ \\
\hline 0.dummy_16 & - & - & - & - & - & - & - & - \\
\hline \multirow[t]{2}{*}{ cut1 } & $-4,055^{* * *}$ & $-3,705^{* * *}$ & $-3,922^{* * *}$ & $-1,417^{* *}$ & -1094 & $-2,381 * * *$ & $-6,329 * * *$ & $-3,477^{* * *}$ \\
\hline & $-1,068$ & $(0,720)$ & $(0,928)$ & $(0,570)$ & $(0,693)$ & $(0,829)$ & -1066 & $(0,630)$ \\
\hline \multirow[t]{2}{*}{ cut2 } & $-0,0476$ & 0,283 & $-0,186$ & $1,962^{* * *}$ & $1,772^{* *}$ & 0,948 & $-1,638^{*}$ & $-0,394$ \\
\hline & $-1,097$ & $(0,760)$ & $(0,873)$ & $(0,598)$ & $(0,716)$ & $(0,833)$ & $(0,857)$ & $(0,645)$ \\
\hline \multirow[t]{2}{*}{ sigma2_u } & $0,883^{* * *}$ & $1,110^{\star * *}$ & $1,146^{* * *}$ & $1,471^{* \star *}$ & $0,372^{* * *}$ & $0,656^{* * *}$ & $0,836^{* * *}$ & $0,569 * * *$ \\
\hline & $(0,312)$ & $(0,334)$ & $(0,378)$ & $(0,341)$ & $(0,130)$ & $(0,191)$ & $(0,303)$ & $(0,163)$ \\
\hline Observations & 462 & 463 & 462 & 463 & 462 & 463 & 463 & 463 \\
\hline Number of id & 93 & 93 & 93 & 93 & 93 & 93 & 93 & 93 \\
\hline
\end{tabular}

Fuente: elaboración propia. Errores estándares en paréntesis. *** $p<0,01, * * p<0,05,{ }^{*} p<0,1$. 
Con relación a las variables de control, se observa que un aumento en metros cuadrados de áreas verdes por habitante afecta de forma negativa y significativa el rango de calidad de vida urbana en general, y en particular la dimensión de vivienda en los tres modelos, lo que sugiere mejoras en el ranquin. Las áreas verdes son sinónimo de mejoras urbanas que fomentan la vida al aire libre y el encuentro social, embellecen el entorno y generan plusvalía en las propiedades. Por otra parte, la variable criminalidad per cápita y motorización arrojan un signo negativo, en general, y son estadísticamente significativas para explicar el índice agregado, lo cual se traduce en que las comunas con mayor criminalidad e índice de motorización tienden a estar más arriba en los niveles de calidad de vida urbana. Esto puede ser reflejo de que las ciudades con mayor calidad de vida tienden a tener una mayor cantidad de automóviles y tasas de crimen. En particular, para el caso del índice de motorización, a pesar de sugerir un incremento en los niveles de calidad de vida en las dimensiones sociocultural y salud, los resultados arrojan un efecto positivo en las dimensiones de conectividad y negocios, lo que implica una baja en el ranquin para las comunas que padecen un mayor parque vehicular en esta dimensión en particular.

Para el caso de la variable profesionalización del personal municipal, esta tiene un efecto negativo en la dimensión sociocultural en el modelo sin rezagos, aumentando la calidad de vida, mientras que en la dimensión laboral presenta un signo opuesto. En el caso de la variable que recoge diferencias en temperatura se tiene un aumento en la calidad de vida en la dimensión de negocios y en todos los modelos, así como una disminución, en particular, en la dimensión de conectividad. Lo anterior puede explicarse por el hecho de que la variabilidad climática puede ser un elemento positivo para la diversificación de la actividad económica y los negocios, pero al mismo tiempo implicar eventos naturales extremos que afectan la conectividad. Finalmente, mayores tasas de criminalidad parecen ser más frecuentes en comunas con mayores niveles de recursos.

En relación con las variables de interés, en primera instancia se tiene que mayores gastos totales per cápita aumentan la calidad de vida urbana en las dimensiones sociocultural, salud y vivienda en los modelos sin rezagos y con un rezago de un año. En contraste, esta variable provoca un aumento en el rango en la dimensión laboral para el modelo t-1, lo cual sugiere una reducción de la calidad de vida urbana. Los gastos totales per cápita rezagados un año continúan impactando positivamente los niveles de calidad de vida en general, así como en las dimensiones conectividad, laboral y vivienda.

Tabla 3. Modelo probit ordenado con efecto aleatorio datos de panel con rezagos t-1 años

\begin{tabular}{|c|c|c|c|c|c|c|c|c|}
\hline Variables & $\begin{array}{l}\text { Rango } \\
\text { ICVU }\end{array}$ & $\begin{array}{l}\text { Rango } \\
\text { ICVU }\end{array}$ & $\begin{array}{l}\text { Rang } \\
\text { sociocultural }\end{array}$ & $\begin{array}{l}\text { Rango } \\
\text { conectividad }\end{array}$ & $\begin{array}{l}\text { Rango } \\
\text { salud }\end{array}$ & $\begin{array}{l}\text { Rango } \\
\text { laboral }\end{array}$ & $\begin{array}{l}\text { Rango } \\
\text { negocios }\end{array}$ & $\begin{array}{l}\text { Rango } \\
\text { vivienda }\end{array}$ \\
\hline \multicolumn{9}{|c|}{ Estructura de Gastos Municipales per cápita } \\
\hline \multirow{2}{*}{ Gasto municipal } & 0,00219 & 0,00300 & $-0,00836^{* *}$ & $-0,00752$ & $-0,00177$ & $0,00456^{*}$ & $-0,00236$ & $-0,00622^{* *}$ \\
\hline & $(0,00292)$ & $(0,00279)$ & $(0,00352)$ & $(0,00485)$ & $(0,00219)$ & $(0,00262)$ & $(0,00334)$ & $(0,00267)$ \\
\hline \multirow{2}{*}{$\begin{array}{l}\text { Gasto municipal } \\
(\mathrm{t}-1)\end{array}$} & $-0,000141$ & $-0,000705^{*}$ & 0,000896 & $-0,00181^{* *}$ & $-0,000300$ & $-0,000914^{* * *}$ & $-0,000413$ & $-0,000775^{* * *}$ \\
\hline & $(0,000476)$ & $(0,000362)$ & $(0,000581)$ & $(0,000815)$ & $(0,000227)$ & $(0,000327)$ & $(0,000360)$ & $(0,000278)$ \\
\hline \multirow{2}{*}{$\begin{array}{l}\text { Gasto municipal } \\
\text { en educación }\end{array}$} & $-0,0122^{* *}$ & & $3,09 \mathrm{e}-06$ & & & & & \\
\hline & $(0,00524)$ & & $(1,94 \mathrm{e}-06)$ & & & & & \\
\hline \multirow{2}{*}{$\begin{array}{l}\text { Gasto municipal } \\
\text { en educación (t-1) }\end{array}$} & 0,00515 & & $-0,00615^{* *}$ & & & & & \\
\hline & $(0,00541)$ & & $(0,00304)$ & & & & & \\
\hline
\end{tabular}




\begin{tabular}{|c|c|c|c|c|c|c|c|c|}
\hline Variables & $\begin{array}{l}\text { Rango } \\
\text { ICVU }\end{array}$ & $\begin{array}{l}\text { Rango } \\
\text { ICVU }\end{array}$ & $\begin{array}{l}\text { Rang } \\
\text { sociocultural }\end{array}$ & $\begin{array}{l}\text { Rango } \\
\text { conectividad }\end{array}$ & $\begin{array}{l}\text { Rango } \\
\text { salud }\end{array}$ & $\begin{array}{l}\text { Rango } \\
\text { laboral }\end{array}$ & $\begin{array}{l}\text { Rango } \\
\text { negocios }\end{array}$ & $\begin{array}{l}\text { Rango } \\
\text { vivienda }\end{array}$ \\
\hline \multirow{2}{*}{$\begin{array}{l}\text { Gasto municipal } \\
\text { en salud }\end{array}$} & \multicolumn{4}{|l|}{$0,0230^{* *}$} & \multicolumn{4}{|l|}{$0,0208^{* *}$} \\
\hline & \multicolumn{4}{|l|}{$(0,0105)$} & \multicolumn{4}{|c|}{$(0,00953)$} \\
\hline \multirow{2}{*}{$\begin{array}{l}\text { Gasto municipal } \\
\text { en salud (t-1) }\end{array}$} & \multicolumn{4}{|l|}{$-0,0148$} & \multicolumn{4}{|l|}{$-0,01000$} \\
\hline & \multicolumn{4}{|l|}{$(0,0138)$} & \multicolumn{4}{|l|}{$(0,0104)$} \\
\hline
\end{tabular}

\section{Estructura de ingresos municipales per cápita}

\begin{tabular}{lllllllll}
$\begin{array}{l}\text { Ingreso propios } \\
\text { permanentes }\end{array}$ & $-0,00693$ & $-0,00594$ & 0,00337 & 0,00255 & $-0,00692^{* *}$ & $-0,0135^{* * *}$ & $-0,00534$ & 0,000374 \\
\cline { 2 - 8 } & $(0,00424)$ & $(0,00397)$ & $(0,00389)$ & $(0,00478)$ & $(0,00326)$ & $(0,00337)$ & $(0,00401)$ & $(0,00306)$ \\
\hline $\begin{array}{l}\text { Ingreso permiso } \\
\text { circulación }\end{array}$ & $-0,0156$ & & 0,0232 & & & & \\
\cline { 2 - 8 }
\end{tabular}

\section{Estructura de inversión municipal per cápita}

\begin{tabular}{|c|c|c|c|c|c|c|c|c|}
\hline \multirow{2}{*}{$\begin{array}{l}\text { Inversión } \\
\text { municipal }\end{array}$} & 0,00388 & $-0,00179$ & $-0,00556$ & $-0,00856$ & 0,00168 & $-0,0106$ & 0,00208 & 0,0104 \\
\hline & $(0,00918)$ & $(0,00885)$ & $(0,0107)$ & $(0,0136)$ & $(0,0104)$ & $(0,0118)$ & $(0,00882)$ & $(0,00924)$ \\
\hline \multirow{2}{*}{$\begin{array}{l}\text { Inversión } \\
\text { municipal (t-1) }\end{array}$} & $-0,00995$ & $-0,0124$ & $-0,00336$ & $-0,00287$ & $-0,00114$ & 0,000778 & 0,0102 & $-0,0238^{* * *}$ \\
\hline & $(0,00853)$ & $(0,00869)$ & $(0,00973)$ & $(0,0113)$ & $(0,0128)$ & $(0,0104)$ & $(0,00840)$ & $(0,00871)$ \\
\hline \multirow{2}{*}{$\begin{array}{l}\text { Inversión en } \\
\text { educación }\end{array}$} & 0,00775 & & 0,00544 & & & & & \\
\hline & $(0,0292)$ & & $(0,0301)$ & & & & & \\
\hline \multirow{2}{*}{$\begin{array}{l}\text { Inversión en } \\
\text { educación (t-1) }\end{array}$} & 0,00367 & & 0,0154 & & & & & \\
\hline & $(0,0411)$ & & $(0,0441)$ & & & & & \\
\hline \multirow{2}{*}{ Inversión en salud } & $-0,0190$ & & & & 0,00348 & & & \\
\hline & $(0,0567)$ & & & & $(0,0789)$ & & & \\
\hline \multirow{2}{*}{$\begin{array}{l}\text { Inversión en salud } \\
(\mathrm{t}-1)\end{array}$} & $0,0599 * *$ & & & & 0,0198 & & & \\
\hline & $(0,0304)$ & & & & $(0,0151)$ & & & \\
\hline \multicolumn{9}{|c|}{ Variables de control } \\
\hline \multirow{2}{*}{$\begin{array}{l}\text { Nivel de } \\
\text { profesionalización }\end{array}$} & $-0,0193$ & $-0,0181$ & $-0,0236$ & 0,0132 & 0,00102 & $0,0294^{* *}$ & 0,0126 & 0,00835 \\
\hline & $(0,0176)$ & $(0,0186)$ & $(0,0162)$ & $(0,0217)$ & $(0,0102)$ & $(0,0124)$ & $(0,0137)$ & $(0,0130)$ \\
\hline \multirow{2}{*}{ Áreas verdes } & $-0,1000^{* *}$ & $-0,117^{* *}$ & $-0,0335$ & $-0,0476$ & $-0,0357$ & 0,0307 & $-0,0141$ & $-0,153^{* * *}$ \\
\hline & $(0,0463)$ & $(0,0520)$ & $(0,0524)$ & $(0,0822)$ & $(0,0332)$ & $(0,0389)$ & $(0,0418)$ & $(0,0397)$ \\
\hline \multirow{2}{*}{$\begin{array}{l}\text { Índice de } \\
\text { motorización }\end{array}$} & $-0^{* *}$ & $-0^{* *}$ & 0 & $0^{*}$ & $-0^{*}$ & 0 & $0^{* * *}$ & 0 \\
\hline & 0 & 0 & 0 & 0 & 0 & 0 & 0 & 0 \\
\hline \multirow{2}{*}{ Temperatura } & 0,000126 & 0,00426 & $-0,00581$ & $0,0715^{* *}$ & $-0,00931$ & $-0,00603$ & $-0,0414^{* * *}$ & $-0,0269$ \\
\hline & $(0,0177)$ & $(0,0203)$ & $(0,0202)$ & $(0,0285)$ & $(0,0107)$ & $(0,0168)$ & $(0,0140)$ & $(0,0173)$ \\
\hline \multirow{2}{*}{ Criminalidad } & $-37,17$ & $-53,45^{* *}$ & 8,853 & $-42,90$ & $31,40^{* *}$ & $-18,36$ & $-69,40 * * *$ & 5,963 \\
\hline & $(29,25)$ & $(26,73)$ & $(18,98)$ & $(26,49)$ & $(14,06)$ & $(12,09)$ & $(19,51)$ & $(12,84)$ \\
\hline \multirow[t]{2}{*}{ 0.dummy_12 } & $-2,248^{*}$ & $-2,932^{* * *}$ & $-9,288^{* * *}$ & $-0,991$ & $7,573^{* * *}$ & $7,738^{* * *}$ & $7,161^{* * *}$ & $-1,770$ ** \\
\hline & -1269 & $(0,841)$ & -1002 & -1004 & -1040 & $(0,922)$ & $(0,772)$ & $(0,735)$ \\
\hline
\end{tabular}




\begin{tabular}{lllllllllll} 
Variables & $\begin{array}{l}\text { Rango } \\
\text { IcvU }\end{array}$ & $\begin{array}{l}\text { Rango } \\
\text { Icvu }\end{array}$ & $\begin{array}{l}\text { Rang } \\
\text { sociocultural }\end{array}$ & $\begin{array}{l}\text { Rango } \\
\text { conectividad }\end{array}$ & $\begin{array}{l}\text { Rango } \\
\text { salud }\end{array}$ & $\begin{array}{l}\text { Rango } \\
\text { laboral }\end{array}$ & $\begin{array}{l}\text { Rango } \\
\text { negocios }\end{array}$ & $\begin{array}{l}\text { Rango } \\
\text { vivienda }\end{array}$ \\
\hline dummy_13 & $-0,294$ & $-0,143$ & $-0,723^{* * *}$ & $-0,413$ & 0,0168 & 0,0808 & 0,00972 & $-0,521^{*}$ \\
\hline & $(0,361)$ & $(0,298)$ & $(0,230)$ & $(0,410)$ & $(0,226)$ & $(0,238)$ & $(0,290)$ & $(0,270)$ \\
\hline dummy_14 & 0,0214 & 0,140 & $-0,316$ & 0,156 & 0,0554 & 0,0781 & $-0,286$ & $-0,241$ \\
\hline & $(0,312)$ & $(0,281)$ & $(0,248)$ & $(0,333)$ & $(0,227)$ & $(0,237)$ & $(0,275)$ & $(0,221)$ \\
\hline dummy_15 & $-0,156$ & $-0,0517$ & $-0,0520$ & 0,188 & 0,0465 & 0,230 & $-0,0746$ & $-0,524^{* * *}$ \\
\hline & $(0,292)$ & $(0,283)$ & $(0,263)$ & $(0,216)$ & $(0,181)$ & $(0,195)$ & $(0,274)$ & $(0,171)$ \\
\hline 0.dummy_16 & - & - & - & - & - & - & - & - \\
\hline cut1 & $-4,925^{* * *}$ & $-4,852^{* * *}$ & $-5,108^{* * *}$ & $-3,259^{* *}$ & -1225 & $-2,128^{* * *}$ & $-6,326^{* * *}$ & $-4,598^{* * *}$ \\
\hline & $-1,420$ & -1005 & $-1,090$ & $-1,395$ & $(0,768)$ & $(0,784)$ & -1170 & $(0,808)$ \\
\hline cut2 & $-0,633$ & $-0,580$ & -1004 & $2,626^{* *}$ & $1,713^{* *}$ & $1,431^{*}$ & $-1,712^{*}$ & $-1,305^{*}$ \\
\hline & $-1,367$ & $(0,950)$ & $-1,021$ & $-1,266$ & $(0,794)$ & $(0,795)$ & $(0,905)$ & $(0,786)$ \\
\hline sigma2_u & $1,354^{* * *}$ & $1,521^{* * *}$ & $1,327^{* * *}$ & $7,139^{* * *}$ & $0,538^{* *}$ & $0,793^{* * *}$ & $0,687^{* *}$ & $0,793^{* * *}$ \\
\hline & $(0,489)$ & $(0,478)$ & $(0,467)$ & $-2,715$ & $(0,213)$ & $(0,238)$ & $(0,331)$ & $(0,245)$ \\
\hline Observations & 369 & 370 & 369 & 370 & 369 & 370 & 370 & 370 \\
\hline Number of id & 93 & 93 & 93 & 93 & 93 & 93 & 93 & 93 \\
\hline
\end{tabular}

Fuente: elaboración propia. Errores estándares en paréntesis. *** $p<0,01, * * p<0,05, * p<0,1$.

Cuando se desagrega el gasto municipal, los resultados muestran una asociación positiva entre gasto en educación y la calidad de vida urbana en los modelos no rezagados y con un año rezagado. En contraste, el gasto en educación parece estar negativamente relacionado con la calidad de vida urbana en la dimensión sociocultural. Por otra parte, la variable gasto municipal en salud per cápita presenta un efecto negativo en la calidad de vida urbana y, en particular, para la dimensión salud se tiene un efecto negativo en todos los modelos estimados.

Con respecto a la estructura de ingresos, se observa un efecto positivo de los ingresos permanentes en el índice general de calidad de vida urbana en el modelo sin rezagos, en la dimensión de salud y laboral en todos los modelos. Este resultado sugiere que los municipios que realizan mayores esfuerzos en la generación de recursos propios podrían presentar ventajas en términos de financiamiento y gestión que propicien decisiones con menores restricciones, lo que se traduciría en una mejora en los ránquines de calidad de vida urbana.

Finalmente, en relación con la inversión municipal, se encuentra solo una asociación positiva con la calidad de vida en los modelos con rezagos, lo cual sugiere un efecto no inmediato de la inversión como esperado, en particular en el ranquin de la dimensión vivienda. Los resultados para la inversión coinciden con los argumentos de Raczynski y Serrano (2001) y Bardhan (2002), quienes discuten los múltiples beneficios que la inversión pública local tiene para el desarrollo de los territorios a mediano y largo plazo. Adicionalmente, los resultados no muestran asociaciones significativas entre la estructura de inversión en educación y salud en los índices de calidad de vida urbana. 
Tabla 4. Modelo probit ordenado con efecto aleatorio datos de panel con rezagos t-1 y t-2

\begin{tabular}{|c|c|c|c|c|c|c|c|c|}
\hline Variables & $\begin{array}{l}\text { Rango } \\
\text { icvu }\end{array}$ & $\begin{array}{l}\text { Rango } \\
\text { icvu }\end{array}$ & \begin{tabular}{|l|} 
Rango \\
sociocultural
\end{tabular} & $\begin{array}{l}\text { Rango } \\
\text { conectividad }\end{array}$ & Rango salud & $\begin{array}{l}\text { Rango } \\
\text { laboral }\end{array}$ & $\begin{array}{l}\text { Rango } \\
\text { negocios }\end{array}$ & $\begin{array}{l}\text { Rango } \\
\text { vivienda }\end{array}$ \\
\hline \multicolumn{9}{|c|}{ Estructura de gastos municipales per cápita } \\
\hline \multirow{2}{*}{ Gasto municipal } & 0,000362 & 0,00102 & $-0,00480$ & 0,000590 & $-0,00115$ & $0,00505^{*}$ & $-0,00364$ & $-0,00770^{*}$ \\
\hline & $(0,00391)$ & $(0,00388)$ & $(0,00410)$ & $(0,00699)$ & $(0,00289)$ & $(0,00293)$ & $(0,00332)$ & $(0,00440)$ \\
\hline \multirow{2}{*}{$\begin{array}{l}\text { Gasto municipal } \\
(\mathrm{t}-1)\end{array}$} & $-0,00137$ & 0,000938 & $0,0132^{* * *}$ & $-0,00128$ & $-0,00207$ & $-0,00725^{* *}$ & $-0,000364$ & 0,00428 \\
\hline & $(0,00371)$ & $(0,00264)$ & $(0,00470)$ & $(0,00596)$ & $(0,00356)$ & $(0,00359)$ & $(0,00403)$ & $(0,00544)$ \\
\hline \multirow{2}{*}{$\begin{array}{l}\text { Gasto municipal } \\
(\mathrm{t}-2)\end{array}$} & 0,00138 & $-0,00173$ & $-0,0131^{* * *}$ & $-0,000921$ & 0,00183 & $0,00661 *$ & $-3,12 e-05$ & $-0,00590$ \\
\hline & $(0,00393)$ & $(0,00292)$ & $(0,00508)$ & $(0,00633)$ & $(0,00379)$ & $(0,00377)$ & $(0,00415)$ & $(0,00585)$ \\
\hline \multirow{2}{*}{$\begin{array}{l}\text { Gasto municipal } \\
\text { en educación }\end{array}$} & $-0,00232$ & & $9,81 \mathrm{e}-06^{* * *}$ & & & & & \\
\hline & $(0,00743)$ & & $(3,75 e-06)$ & & & & & \\
\hline \multirow{2}{*}{$\begin{array}{l}\text { Gasto municipal } \\
\text { en educación (t-1) }\end{array}$} & 0,00736 & & 0,000222 & & & & & \\
\hline & $(0,00594)$ & & $(0,00606)$ & & & & & \\
\hline \multirow{2}{*}{$\begin{array}{l}\text { Gasto municipal } \\
\text { en educación (t-2) }\end{array}$} & $-0,0135^{*}$ & & $-0,00933$ & & & & & \\
\hline & $(0,00718)$ & & $(0,00616)$ & & & & & \\
\hline \multirow{2}{*}{$\begin{array}{l}\text { Gasto municipal } \\
\text { en salud }\end{array}$} & 0,0123 & & & & $0,0240^{* *}$ & & & \\
\hline & $(0,0162)$ & & & & $(0,0118)$ & & & \\
\hline \multirow{2}{*}{$\begin{array}{l}\text { Gasto municipal } \\
\text { en salud (t-1) }\end{array}$} & $-0,0247$ & & & & $-0,0222$ & & & \\
\hline & $(0,0196)$ & & & & $(0,0170)$ & & & \\
\hline \multirow{2}{*}{$\begin{array}{l}\text { Gasto municipal } \\
\text { en salud (t-2) }\end{array}$} & 0,0309 & & & & 0,00963 & & & \\
\hline & $(0,0198)$ & & & & $(0,0130)$ & & & \\
\hline
\end{tabular}

\section{Estructura de ingresos municipales per cápita}

\begin{tabular}{|c|c|c|c|c|c|c|c|c|}
\hline \multirow{2}{*}{$\begin{array}{l}\text { Ingreso propios } \\
\text { permanentes }\end{array}$} & $-0,00561$ & $-0,00358$ & $-0,00201$ & $-0,00698$ & $-0,00732^{*}$ & $-0,0148^{* * *}$ & $-0,00329$ & $-0,00525$ \\
\hline & $(0,00613)$ & $(0,00589)$ & $(0,00545)$ & $(0,00963)$ & $(0,00424)$ & $(0,00402)$ & $(0,00415)$ & $(0,00662)$ \\
\hline \multirow{2}{*}{$\begin{array}{l}\text { Ingreso permiso } \\
\text { circulación }\end{array}$} & $-0,00693$ & & & 0,00295 & & & & \\
\hline & $(0,0175)$ & & & $(0,0319)$ & & & & \\
\hline
\end{tabular}

Estructura de inversión municipal per cápita

\begin{tabular}{|c|c|c|c|c|c|c|c|c|}
\hline \multirow{2}{*}{$\begin{array}{l}\text { Inversión } \\
\text { municipal }\end{array}$} & 0,00228 & $-0,00257$ & $-0,00788$ & $-0,0112$ & 0,00304 & $-0,00581$ & 0,00111 & 0,0106 \\
\hline & $(0,0108)$ & $(0,0105)$ & $(0,0105)$ & $(0,0145)$ & $(0,0108)$ & $(0,0127)$ & $(0,00958)$ & $(0,0145)$ \\
\hline \multirow{2}{*}{$\begin{array}{l}\text { Inversión } \\
\text { municipal (t-1) }\end{array}$} & $-0,0277^{* * *}$ & $-0,0286^{* * *}$ & $-0,00132$ & 0,000336 & 0,00168 & $-0,00646$ & $-0,00775$ & $-0,0315^{* * *}$ \\
\hline & $(0,00727)$ & $(0,00702)$ & $(0,0142)$ & $(0,0122)$ & $(0,0148)$ & $(0,0117)$ & $(0,0124)$ & $(0,0117)$ \\
\hline \multirow{2}{*}{$\begin{array}{l}\text { Inversión } \\
\text { municipal (t-2) }\end{array}$} & 0,0269 & 0,0197 & $-0,00324$ & $-0,0157$ & $-0,00568$ & 0,00203 & 0,0252 & 0,00978 \\
\hline & $(0,0196)$ & $(0,0192)$ & $(0,0139)$ & $(0,0150)$ & $(0,0127)$ & $(0,00876)$ & $(0,0157)$ & $(0,0179)$ \\
\hline \multirow{2}{*}{$\begin{array}{l}\text { Inversión en } \\
\text { educación }\end{array}$} & $-0,00322$ & & $-0,0218$ & & & & & \\
\hline & $(0,0459)$ & & $(0,0387)$ & & & & & \\
\hline \multirow{2}{*}{$\begin{array}{l}\text { Inversión en } \\
\text { educación (t-1) }\end{array}$} & $-0,0218$ & & 0,0201 & & & & & \\
\hline & $(0,0302)$ & & $(0,0420)$ & & & & & \\
\hline
\end{tabular}




\begin{tabular}{|c|c|c|c|c|c|c|c|c|}
\hline Variables & $\begin{array}{l}\text { Rango } \\
\text { icvu }\end{array}$ & $\begin{array}{l}\text { Rango } \\
\text { icvu }\end{array}$ & $\begin{array}{l}\text { Rango } \\
\text { sociocultural }\end{array}$ & $\begin{array}{l}\text { Rango } \\
\text { conectividad }\end{array}$ & Rango salud & \begin{tabular}{|l} 
Rango \\
laboral
\end{tabular} & $\begin{array}{l}\text { Rango } \\
\text { negocios }\end{array}$ & $\begin{array}{l}\text { Rango } \\
\text { vivienda }\end{array}$ \\
\hline \multirow{2}{*}{$\begin{array}{l}\text { Inversión en } \\
\text { educación (t-2) }\end{array}$} & 0,0152 & & 0,0192 & & & & & \\
\hline & $(0,0520)$ & & $(0,0693)$ & & & & & \\
\hline \multirow{2}{*}{ Inversión en salud } & 0,0807 & & & & $-0,0153$ & & & \\
\hline & $(0,0723)$ & & & & $(0,0903)$ & & & \\
\hline \multirow{2}{*}{$\begin{array}{l}\text { Inversión en salud } \\
\text { (t-1) }\end{array}$} & 0,0202 & & & & 0,00360 & & & \\
\hline & $(0,0645)$ & & & & $(0,0649)$ & & & \\
\hline \multirow{2}{*}{$\begin{array}{l}\text { Inversión en salud } \\
(\mathrm{t}-2)\end{array}$} & 0,0384 & & & & $-0,00619$ & & & \\
\hline & $(0,0423)$ & & & & $(0,0407)$ & & & \\
\hline \multicolumn{9}{|c|}{ Variables de control } \\
\hline \multirow{2}{*}{$\begin{array}{l}\text { Nivel de } \\
\text { profesionalización }\end{array}$} & $-0,0221$ & $-0,0140$ & $-0,0219$ & $-0,00639$ & 0,00542 & $0,0377^{* * *}$ & 0,0135 & $-0,0113$ \\
\hline & $(0,0183)$ & $(0,0202)$ & $(0,0180)$ & $(0,0233)$ & $(0,0108)$ & $(0,0141)$ & $(0,0168)$ & $(0,0159)$ \\
\hline \multirow{2}{*}{ Áreas verdes } & $-0,0998^{*}$ & $-0,137^{* * *}$ & $-0,0707$ & $-0,106$ & $-0,0337$ & 0,0138 & $-0,0422$ & $-0,158^{* * *}$ \\
\hline & $(0,0510)$ & $(0,0527)$ & $(0,0530)$ & $(0,0863)$ & $(0,0385)$ & $(0,0325)$ & $(0,0386)$ & $(0,0548)$ \\
\hline \multirow{2}{*}{$\begin{array}{l}\text { Índice de } \\
\text { motorización }\end{array}$} & 0 & 0 & $-0^{* *}$ & 0 & 0 & 0 & $0^{* * *}$ & 0 \\
\hline & 0 & 0 & 0 & 0 & 0 & 0 & 0 & 0 \\
\hline \multirow{2}{*}{ Temperatura } & $-0,00200$ & 0,00935 & $-0,0123$ & $0,0855^{* * *}$ & $-0,0164$ & 0,00567 & $-0,0425^{* * *}$ & $-0,0260$ \\
\hline & $(0,0175)$ & $(0,0211)$ & $(0,0200)$ & $(0,0297)$ & $(0,0123)$ & $(0,0164)$ & $(0,0139)$ & $(0,0254)$ \\
\hline \multirow{2}{*}{ Criminalidad } & $-22,27$ & $-48,99 * *$ & 7191 & $-45,24$ & $39,93^{* * *}$ & $-19,24$ & $-75,46^{* * *}$ & 28,98 \\
\hline & $(22,69)$ & $(23,65)$ & $(22,19)$ & $(30,39)$ & $(15,02)$ & $(13,03)$ & $(19,20)$ & $(20,54)$ \\
\hline \multirow[t]{2}{*}{ o.dummy_12 } & -1955 & $-2,298^{*}$ & $-10,32^{* * *}$ & -1770 & $6,522^{* * *}$ & $8,000^{* * *}$ & $7,372^{* * *}$ & $-2,544^{*}$ \\
\hline & -1861 & -1251 & -1305 & -1296 & -1210 & $(0,953)$ & $(0,881)$ & -1317 \\
\hline \multirow[t]{2}{*}{ 0.dummy_13 } & $10,74^{\star * *}$ & $9,101^{* * *}$ & $-13,46^{* * *}$ & -1498 & $7,793^{* * *}$ & $1,724^{* *}$ & $8,182^{* * *}$ & $-10,53^{* * *}$ \\
\hline & -2075 & -1362 & -1972 & -1419 & -1394 & $(0,866)$ & -1343 & -1568 \\
\hline \multirow[t]{2}{*}{ dummy_14 } & 0,120 & 0,132 & $-0,216$ & 0,299 & 0,0276 & 0,0665 & $-0,297$ & $-0,362$ \\
\hline & $(0,327)$ & $(0,288)$ & $(0,240)$ & $(0,351)$ & $(0,227)$ & $(0,247)$ & $(0,265)$ & $(0,315)$ \\
\hline \multirow[t]{2}{*}{ dummy_15 } & $-0,0543$ & $-0,0455$ & $-0,173$ & 0,236 & 0,0392 & 0,317 & $-0,0370$ & $-0,761^{* * *}$ \\
\hline & $(0,284)$ & $(0,280)$ & $(0,260)$ & $(0,245)$ & $(0,187)$ & $(0,201)$ & $(0,272)$ & $(0,226)$ \\
\hline 0.dummy_16 & - & - & - & - & - & - & - & - \\
\hline \multirow[t]{2}{*}{ cut1 } & $-4,199 * * *$ & $-4,650 * * *$ & $-5,515^{\star * *}$ & $-3,171^{* *}$ & -1039 & $-1,722^{*}$ & $-6,591^{* * *}$ & $-5,910 * * *$ \\
\hline & -1443 & -1091 & -1313 & -1389 & $(0,843)$ & $(0,883)$ & -1213 & -1299 \\
\hline \multirow[t]{2}{*}{ cut2 } & 0,0125 & $-0,418$ & -1404 & $2,651^{* *}$ & 1,820 ** & $1,992 * *$ & $-1,951^{* *}$ & -1588 \\
\hline & -1333 & $(0,976)$ & -1130 & -1279 & $(0,871)$ & $(0,896)$ & $(0,902)$ & -1136 \\
\hline \multirow[t]{2}{*}{ sigma2_u } & $1,287^{* *}$ & $1,718^{* * *}$ & $1,347^{* *}$ & $6,478^{* * *}$ & $0,617^{* *}$ & $0,699 * *$ & $0,734^{*}$ & $1,878^{* * *}$ \\
\hline & $(0,591)$ & $(0,654)$ & $(0,565)$ & -2483 & $(0,274)$ & $(0,285)$ & $(0,381)$ & $(0,661)$ \\
\hline Observations & 276 & 277 & 276 & 277 & 276 & 277 & 277 & 277 \\
\hline Number of id & 93 & 93 & 93 & 93 & 93 & 93 & 93 & 93 \\
\hline
\end{tabular}

Fuente: elaboración propia. Errores estándares en paréntesis. *** $p<0,01, * * p<0,05,{ }^{*} p<0,1$. 


\section{Conclusiones}

Dentro de un contexto en el que se considera que los gobiernos locales pueden incidir en la calidad de vida de sus habitantes, este estudio modela los efectos de la estructura de gastos, ingreso e inversión de los gobiernos locales como factores relevantes de la calidad de vida urbana en Chile. En concordancia con la forma de medir la calidad de vida urbana sobre la base de un ranquin, este trabajo estima un modelo probit ordenado para datos de panel con efectos aleatorios.

Considerando el conjunto de dimensiones del índice de calidad de vida urbana, los resultados muestran que la estructura de gastos, ingresos e inversión inciden de forma significativa en la calidad de vida urbana. En particular, se destaca la influencia de los gastos municipales en la calidad de vida urbana, exceptuando la dimensión negocios, que solo es afectada por variables de control. Los ingresos permanentes tienen un impacto más evidente en las dimensiones salud y laboral, mientras que la inversión influye con mayor claridad en la dimensión vivienda. Los efectos de la inversión son más notorios en modelos con rezagos, lo cual sugiere un tiempo para que la inversión se materialice en efectos concretos en calidad de vida urbana.

Este trabajo muestra la preponderancia de la estructura de gastos e inversión, sugiriendo que los gobiernos locales pueden desarrollar estrategias de focalización de los gastos e inversiones a fin de lograr mejores resultados en términos de calidad de vida urbana. También emergen como relevantes las estrategias para promover la generación de ingresos propios.

Dentro de las preguntas para investigación futura se plantea la necesidad de extender el análisis a la calidad de vida, mirada desde el punto de vista subjetivo, así como explorar de esta manera si los resultados para la estructura de gastos e ingresos se mantienen cuando se incorporan conceptos tales como niveles de satisfacción individual o felicidad. Asimismo, podría ser relevante evaluar los efectos sobre la calidad de vida urbana que se pueden derivar, potencialmente, desde cambios en la carga fiscal municipal, así como en la gestión y eficiencia de los gobiernos locales, principalmente aquellas vinculadas con las actividades productivas o de los cambios en las asignaciones presupuestarias. Estos son aspectos que se escapan del alcance de este estudio y, por tanto, se dejan para una futura de investigación.

\section{Referencias}

Appleton, S. y Song, L. (2008). Life satisfaction in urban China: component and determinants. World Development, 36(11), 2325-2340.

Bardhan, P. (2002). Decentralization of governance and development. Journal of Economic Perspectives, 16(4),185-205.

Blomquist, G. C., Berger, M. C. y Hoehn, J. P. (1988). New estimates of quality of life in urban areas. The American Economic Review, 78(1), 89-107.

Bonet, J., Zapata, G. y Rueda, F. (2012). Calidad de vida urbana e inversiones públicas locales: el caso de Manizales (Colombia) (Notas técnicas \# IDB-TN-405). Washington: Banco Interamericano de Desarrollo.

Cabrer, B., Sancho, A. y Serrano, G. (2001). Microeconometría y decisión. Madrid: Ediciones Pirámide.

Fadda, G. y Jirón, P. (2002). Incorporación del concepto de calidad de vida (CV) a las políticas de desarrollo urbano y habitacional en Chile. Ponencia presentada en el Congreso Internacional del Medio Ambiente y Desarrollo Sustentable, realizado del 28 al 31 de octubre, Universidad de Valparaíso,Viña del Mar, Chile.

Fuentes, L., Allard, P. y Orellana, A. (2007). El municipio y la gobernabilidad del territorio comunal. En T. Matus (Coord.), La reforma municipal en la mira (pp. 43-84). Santiago de Chile: Expansiva, Observatorio de Ciudades uc, Escuela de Trabajo Social uc.

Giannias, D. A. (1998). A quality of life based ranking of Canadian cities. Urban Studies, 35(12), 2241-2251.

Greene, W. H. (1998) Análisis econométrico. Madrid: Prentice Hall.

Gyourko, J. y Tracy, J. (1991). The structure of local public finance and the quality of life. Journal of Political Economy, 99(4), 774-806.

Henríquez, M. y Fuenzalida, J. (2011). Compensando la desigualdad de ingresos locales: el Fondo Común Municipal (FCM) en Chile. Revista Iberoamericana de Estudios Municipales, 2(4),73-104.

Lambiri, D., Biagi, B. y Royuela, V. (2007). Quality of life in the economic and urban economic literature. Social Indicators Research, 84(1), 1-25. 
Leva, G. (2005). Indicadores de calidad de vida urbana. Teoría y metodología. Quilmes, Argentina: Universidad Nacional de Quilmes.

Orellana, A. (2011). Indicador de calidad de vida urbana. Santiago de Chile: Núcleo de Estudios Metropolitanos del Instituto de Estudios Urbanos UC.

Pacheco, F, Sánchez, R. y Villena, M. (2013). Eficiencia de los gobiernos locales y sus determinantes. Santiago de Chile: Dirección de Presupuestos, Gobierno de Chile.

Precedo L., Míguez, A. y Orosa, J. (2012). La calidad de vida de las ciudades gallegas: una aplicación empírica. Boletín de la Asociación de Geógrafos Españoles 59, 275-299.
Raczynski, D. y Serrano, C. (2001). Descentralización: nudos críticos. Santiago de Chile: Corporación de Investigaciones Económicas para Latinoamérica, Cieplan.

Rosen, S. (1979). Wage-based indexes of urban quality of life. En Current Issues in Urban Economics (pp. 74104). Baltimore, EE. UU.: Johns Hopkins University Press.

Roback, J. (1982). Wages, rents, and the quality of life. Journal of Political Economy, 90(6), 1257-1278.

Stover, M. E. y Leven, C. L. (1992). Methodological issues in the determination of the quality of life in urban areas. Urban Studies, 29(5), 737-754. 


\section{Anexos}

Tabla A1. Comparación Índice de Calidad de Vida Urbana por rangos 2013-2016

\begin{tabular}{|c|c|c|c|c|c|}
\hline & 2012 & 2013 & 2014 & 2015 & 2016 \\
\hline Iquique & Superior & Promedio & Promedio & Promedio & Inferior \\
\hline Alto Hospicio & Inferior & Inferior & Inferior & Inferior & Promedio \\
\hline Antofagasta & Promedio & Promedio & Superior & Promedio & Promedio \\
\hline Calama & Superior & Promedio & Promedio & Promedio & Promedio \\
\hline Copiapó & Promedio & Promedio & Promedio & Promedio & Promedio \\
\hline Vallenar & Promedio & Promedio & Promedio & Promedio & Promedio \\
\hline La Serena & Promedio & Promedio & Promedio & Promedio & Promedio \\
\hline Coquimbo & Promedio & Promedio & Promedio & Promedio & Promedio \\
\hline Ovalle & Promedio & Promedio & Promedio & Promedio & Promedio \\
\hline Valparaíso & Promedio & Promedio & Promedio & Promedio & Promedio \\
\hline Concón & Superior & Superior & Promedio & Promedio & Superior \\
\hline Viña Del Mar & Promedio & Promedio & Promedio & Promedio & Superior \\
\hline Los Andes & Promedio & Promedio & Promedio & Promedio & Promedio \\
\hline Quillota & Promedio & Promedio & Promedio & Promedio & Promedio \\
\hline Calera & Promedio & Promedio & Promedio & Promedio & Promedio \\
\hline San Antonio & Promedio & Promedio & Promedio & Promedio & Promedio \\
\hline San Felipe & Promedio & Promedio & Promedio & Promedio & Promedio \\
\hline Quilpué & Promedio & Promedio & Promedio & Promedio & Promedio \\
\hline Villa Alemana & Promedio & Promedio & Promedio & Promedio & Promedio \\
\hline Rancagua & Promedio & Promedio & Promedio & Promedio & Promedio \\
\hline Machalí & Superior & Promedio & Promedio & Promedio & Promedio \\
\hline Rengo & Promedio & Promedio & Promedio & Promedio & Promedio \\
\hline San Fernando & Promedio & Promedio & Promedio & Promedio & Promedio \\
\hline Talca & Promedio & Promedio & Promedio & Promedio & Promedio \\
\hline Curicó & Promedio & Promedio & Promedio & Promedio & Promedio \\
\hline Linares & Promedio & Promedio & Promedio & Promedio & Promedio \\
\hline Concepción & Promedio & Promedio & Promedio & Superior & Promedio \\
\hline Coronel & Promedio & Promedio & Promedio & Promedio & Promedio \\
\hline Chiguayante & Promedio & Promedio & Promedio & Promedio & Promedio \\
\hline Lota & Promedio & Inferior & Inferior & Promedio & Promedio \\
\hline Penco & Inferior & Promedio & Promedio & Promedio & Promedio \\
\hline San Pedro De La Paz & Promedio & Promedio & Promedio & Promedio & Promedio \\
\hline
\end{tabular}




\begin{tabular}{|c|c|c|c|c|c|}
\hline Talcahuano & Promedio & Promedio & Promedio & Promedio & Promedio \\
\hline Tomé & Promedio & Promedio & Promedio & Promedio & Promedio \\
\hline Hualpén & Promedio & Promedio & Promedio & Promedio & Promedio \\
\hline Los Ángeles & Promedio & Promedio & Promedio & Promedio & Promedio \\
\hline Chillán & Promedio & Promedio & Promedio & Promedio & Promedio \\
\hline Chillán Viejo & Promedio & Promedio & Promedio & Promedio & Promedio \\
\hline San Carlos & Promedio & Promedio & Promedio & Promedio & Promedio \\
\hline Temuco & Promedio & Promedio & Promedio & Promedio & Superior \\
\hline Padre Las Casas & Inferior & Promedio & Promedio & Promedio & Promedio \\
\hline Villarrica & Promedio & Promedio & Promedio & Promedio & Promedio \\
\hline Angol & Promedio & Promedio & Promedio & Promedio & Promedio \\
\hline Puerto Montt & Promedio & Promedio & Promedio & Superior & Promedio \\
\hline Puerto Varas & Promedio & Promedio & Superior & Superior & Superior \\
\hline Castro & Promedio & Promedio & Promedio & Superior & Promedio \\
\hline Osorno & Promedio & Promedio & Promedio & Promedio & Promedio \\
\hline Coihaique & Promedio & Promedio & Promedio & Superior & Superior \\
\hline Punta Arenas & Promedio & Superior & Promedio & Superior & Promedio \\
\hline Santiago & Superior & Superior & Promedio & Superior & Inferior \\
\hline Cerrillos & Promedio & Promedio & Promedio & Inferior & Inferior \\
\hline Cerro Navia & Promedio & Inferior & Inferior & Inferior & Inferior \\
\hline Conchalí & Promedio & Promedio & Inferior & Inferior & Inferior \\
\hline El Bosque & Inferior & Promedio & Inferior & Inferior & Promedio \\
\hline Estación Central & Promedio & Promedio & Promedio & Promedio & Promedio \\
\hline Huechuraba & Promedio & Promedio & Promedio & Promedio & Inferior \\
\hline Independencia & Promedio & Promedio & Inferior & Inferior & Inferior \\
\hline La Cisterna & Promedio & Promedio & Promedio & Promedio & Promedio \\
\hline La Florida & Promedio & Promedio & Promedio & Promedio & Promedio \\
\hline La Granja & Promedio & Promedio & Promedio & Inferior & Inferior \\
\hline La Pintana & Inferior & Inferior & Inferior & Inferior & Promedio \\
\hline La Reina & Superior & Superior & Superior & Superior & Superior \\
\hline Las Condes & Superior & Superior & Superior & Superior & Superior \\
\hline Lo Barnechea & Superior & Superior & Superior & Promedio & Inferior \\
\hline Lo Espejo & Promedio & Inferior & Inferior & Inferior & Inferior \\
\hline Lo Prado & Promedio & Inferior & Inferior & Inferior & Promedio \\
\hline Macul & Promedio & Promedio & Promedio & Promedio & Promedio \\
\hline Maipú & Promedio & Promedio & Promedio & Promedio & Superior \\
\hline
\end{tabular}




\begin{tabular}{|c|c|c|c|c|c|}
\hline Ñuñoa & Superior & Superior & Superior & Superior & Superior \\
\hline Pedro Aguirre Cerda & Inferior & Inferior & Inferior & Inferior & Inferior \\
\hline Peñalolén & Promedio & Promedio & Promedio & Promedio & Promedio \\
\hline Providencia & Superior & Superior & Superior & Superior & Superior \\
\hline Pudahuel & Promedio & Promedio & Promedio & Promedio & Promedio \\
\hline Quilicura & Promedio & Promedio & Promedio & Promedio & Promedio \\
\hline Quinta Normal & Promedio & Promedio & Inferior & Inferior & Inferior \\
\hline Recoleta & Promedio & Promedio & Promedio & Promedio & Inferior \\
\hline Renca & Promedio & Promedio & Promedio & Promedio & Promedio \\
\hline San Joaquín & Promedio & Promedio & Promedio & Inferior & Promedio \\
\hline San Miguel & Promedio & Promedio & Promedio & Promedio & Promedio \\
\hline San Ramón & Promedio & Inferior & Inferior & Inferior & Promedio \\
\hline Vitacura & Superior & Superior & Superior & Superior & Superior \\
\hline Puente Alto & Inferior & Promedio & Promedio & Promedio & Promedio \\
\hline Colina & Promedio & Promedio & Promedio & Promedio & Promedio \\
\hline Lampa & Promedio & Promedio & Promedio & Promedio & Promedio \\
\hline San Bernardo & Promedio & Promedio & Promedio & Promedio & Inferior \\
\hline Buin & Promedio & Promedio & Promedio & Promedio & Promedio \\
\hline Paine & Promedio & Promedio & Promedio & Promedio & Promedio \\
\hline Melipilla & Promedio & Promedio & Promedio & Promedio & Promedio \\
\hline Talagante & Promedio & Promedio & Promedio & Promedio & Promedio \\
\hline Padre Hurtado & Promedio & Promedio & Inferior & Promedio & Promedio \\
\hline Peñaflor & Promedio & Promedio & Promedio & Promedio & Promedio \\
\hline Valdivia & Promedio & Promedio & Promedio & Promedio & Superior \\
\hline Arica & Promedio & Promedio & Promedio & Promedio & Promedio \\
\hline
\end{tabular}

Fuente: elaboración propia. 
